\title{
Effect of Traditional Treatment of Diabetes Mellitus with Xanthosoma sagittifolium on the Male Reproductive System of Alloxan-Induced Diabetic Wistar Rats
}

\author{
Authors \\ Olayinka A. Oridupa ${ }^{1}$, Oluyemisi F. Folasire², Adedotun J. Owolabi², Oluwasanmi Aina ${ }^{3}$
}

Affiliations

1 Department of Veterinary Physiology, Biochemistry \& Pharmacology, University of Ibadan, Ibadan, Nigeria

2 Department of Human Nutrition, University of Ibadan, Ibadan, Nigeria

3 Department of Veterinary Anatomy, University of Ibadan, Nigeria

Key words

Xanthosoma sagittifolium, diabetes mellitus, andrology

received 09.11 .2016

accepted 10.02.2017

Bibliography

DOI http://dx.doi.org/10.1055/s-0043-103575

Published online: 13.3.2017

Drug Res 2017; 67: 337-342

(c) Georg Thieme Verlag KG Stuttgart · New York

ISSN 2194-9379

Correspondence

Olayinka A. Oridupa

Department of Veterinary Physiology

Biochemistry \& Pharmacology

University of Ibadan

Ibadan, Oyo 2000012

Nigeria

Tel.: + 234/805/6666 304

olayinkaolumide2000@yahoo.com

\begin{abstract}
Introduction The management of diabetes mellitus (DM) targets glycemic control as well as prevention or reversal of other complications associated with the metabolic disorder. One of such complications is the infertility which has been traced to oxidative stress and DNA damage caused by DM.

Subjects and methods In this study, experimentally-induced diabetic male Wistar rats were fed with Xanthosoma sagittifolium (cocoyam) for 14 days and its effect on sperm morphology and characteristics, as well as histology of the testes were assessed. X. sagittifolium corm feed (Xs) were reconstituted with commercial rat feed to contain $25,50,75$ or $100 \%$ X. sagittifolium on a weight/weight basis.

Result One primary and 7 secondary cell abnormalities were observed with overall increased total abnormal sperm cells in the diabetic rats. Sperm cell motility was significantly $(p<0.05)$ reduced in all diabetic rats, but diabetic rats fed with Xs showed increased motility and liveability. Sperm volume was unchanged, but the depressed sperm count in the untreated diabetic rats was increased in Xs-fed rats. Histology of $X s-f e d$ diabetic rats showed reduction in seminiferous tubule diameter and luminal diameter which was significantly enlarged in untreated diabetic rats.

Conclusion X. sagittifolium significantly $(p<0.05)$ prevented further deterioration of sperm cell quality and reversed cell apoptosis as presented by increased sperm motility, liveability and count. In the overall, the chances of fertilization by sperm cells from diabetic patients will be increased as well as achievement of good glycemic control and prevention of further damage by the disease condition.
\end{abstract}

\section{Introduction}

Food and medicinal plants have been employed in the world over for traditional prevention, treatment and management of diabetes mellitus (DM) amongst other ailments of man and his animals [1-3]. Diabetes mellitus, a metabolic disorder of the endocrine system involving derangement in carbohydrate metabolism is widespread in the world and not limited to age, sex or race [4]. Type 1 (inherited DM) is not limited to socio-demography, but type 2 has a positive correlation to age and socioeconomic status [5, 6]. Being a lifelong condition, management of DM requires consistent treatment and tight glyceamic control to reduce the risk of development of complications sequel to DM [7].

Reproductive complications associated with DM include disruption of male fertility, impotence, retrograde ejaculation and hypogonadism as researchers have found that the male hypothalamic-pituitary-gonadal axis is regulated by pancreatic insulin, and this is essential for fertility [8-10]. This has invariably led to reduced pregnancy rates in female partners of diabetic males with reduced sperm quality $[11,12]$. Although the exact mechanism is unclear whether it is due to hyperglycemia or abnormal insulin signaling, sperm samples from diabetic males have been shown to have increased percentages of nuclear and mitochondrial DNA damage which suggests that the infertility may be due to hyperglycemia-induced oxidative stress and increased glycation $[8,11,13,14]$. Thus, one of the objectives of management of DM should aim at improving the rate of fertility in male diabetics.

To this end, orthodox and traditional systems of medicines have sought to manage this metabolic derangement. Different indigenous or traditional medicinal systems with established practices for management of DM include Ayurveda, Siddha, Chinese, Korean, Ancient Iranian and African Medicines [15-17]. Some of the herbs utilized in these traditional practices usually have more than one ailment for 


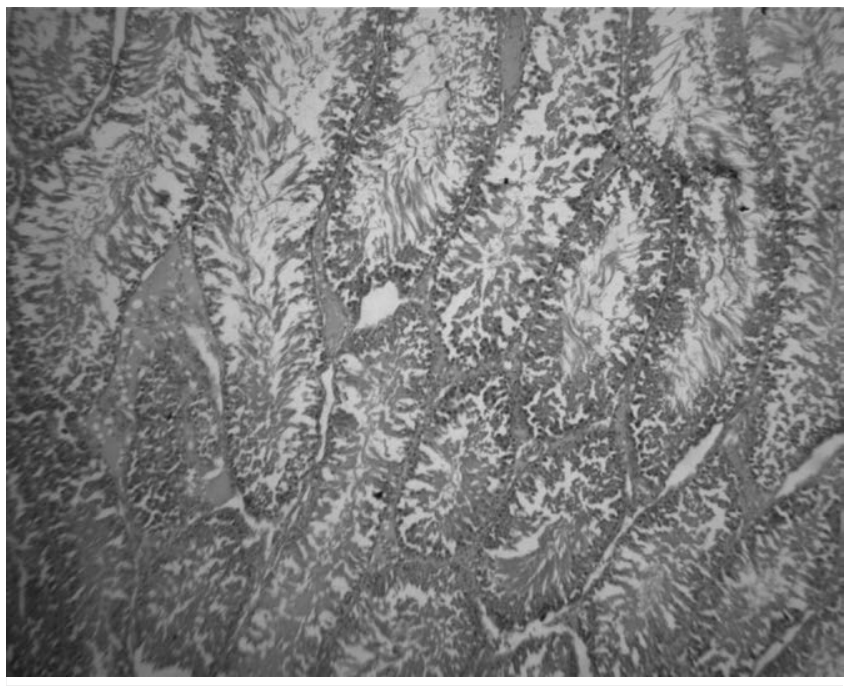

$\checkmark$ Fig. 1 Seminiferous tubule from normoglycemic control rats (H\&E, X100) (Color figure available online only).

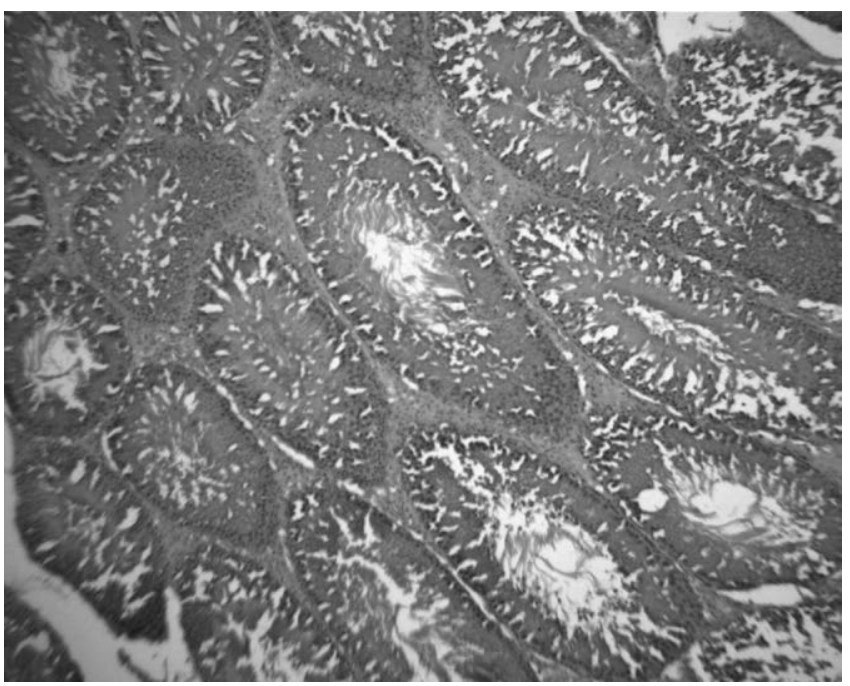

- Fig. 2 Seminiferous tubules from diabetic rats fed with $25 \%$ Xanthosoma sagittifolium (H\&E, X100) (Color figure available online only).

which it is prescribed and as such have multi-organ/system effects, even beyond their intended use [18]. More research are now conducted to verify the local claims of the pharmacological activity(ies) of some plants and also some emphasis is laid on the toxicological profile of these plants [19]. The desired pharmacological and unwanted toxicological effects of the plant in normal individuals, as well as complications of the diseases in question such as infertility in male diabetic patients are considered.

In view of this, one food plant, Xanthosoma sagittifolium (L.) Schott (family Araceae), commonly known as cocoyam, prescribed for management of diabetes mellitus in Nigeria was assessed in this study. Owing to the fact that most organ/system effect of medicinal plants is not limited to the target organ/system, the effect of $X$. sagittifolium on the male reproductive system of diabetic rats was assessed in this study. The study was intended to evaluate the effect of sub-chronic feeding with this low calorie high fibre diet on the male

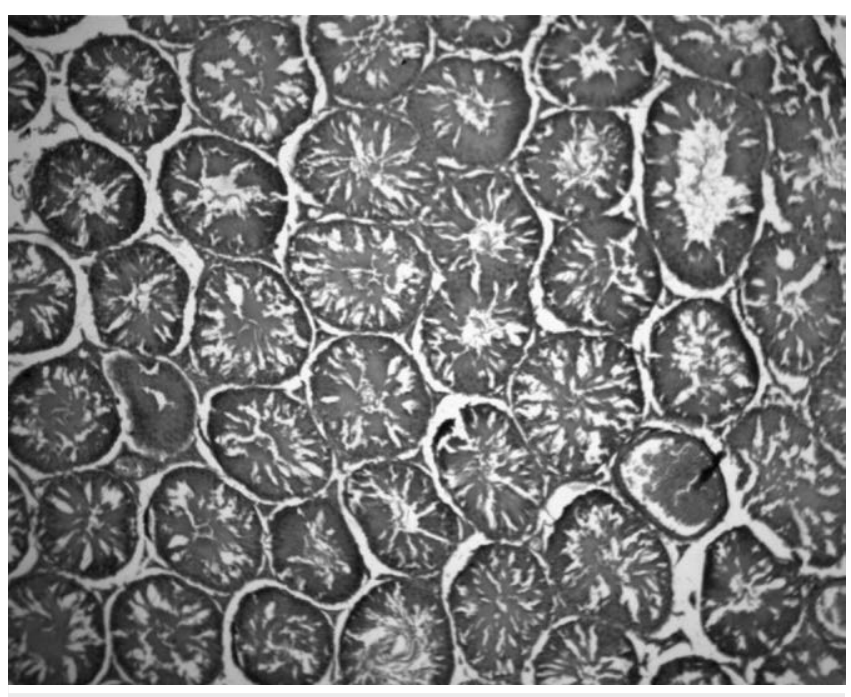

-Fig. 3 Seminiferous tubules from diabetic rats fed with $100 \%$ Xanthosoma sagittifolium (H\&E, X100) (Color figure available online only).

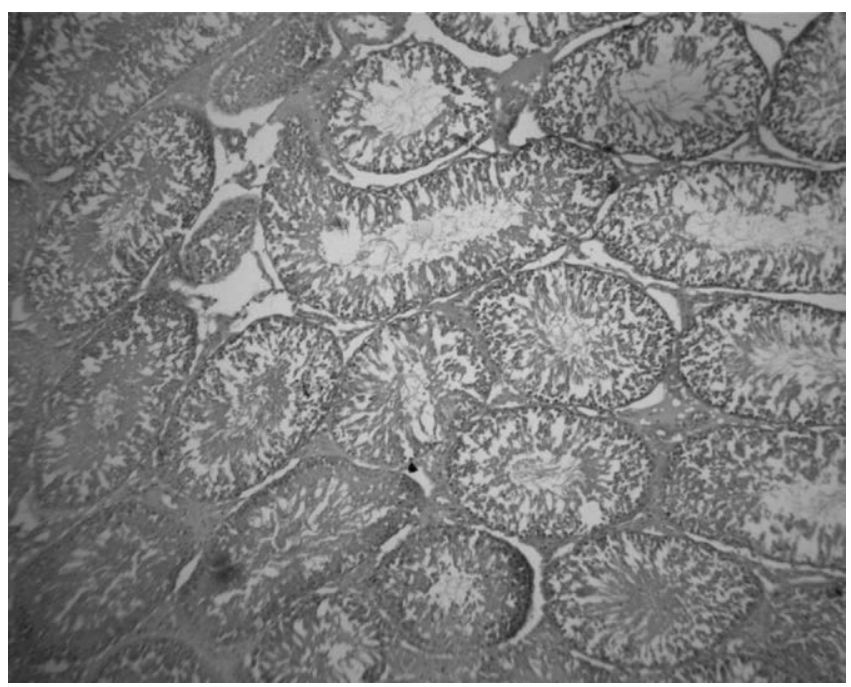

-Fig. 4 Seminiferous tubules from diabetic rats fed with glibenclamide (H\&E, X100) (Color figure available online only).

reproductive system of alloxan-induced diabetic Wistar rats with emphasis on sperm cell morphology and characteristics, as well as histopathology of the seminiferous tubules. ( Fig. 1-6).

\section{Materials and Methods}

Male Wistar rats (140-180 g; 14-16weeks) were obtained from and housed at the Animal House, Department of Physiology, University of Ibadan, Ibadan, Nigeria. The rats were fed with commercially available pelletized rat ration and allowed access to feed and clean water ad libitum. Only normoglycemic rats were included in the study from the start point. The rats were humanely treated in accordance with the Animal Care and Use Ethics of the Faculty of Veterinary Medicine, University of Ibadan. The regulation is in agreement with internationally accepted guide for the Care and Use of laboratory animals. 


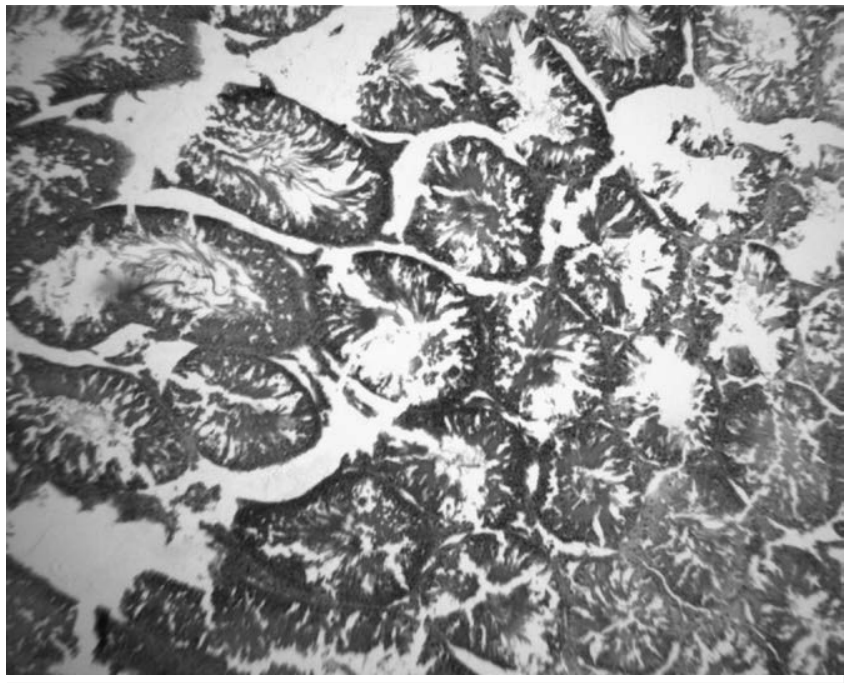

- Fig. 5 Seminiferous tubules from diabetic rats fed with glibenclamide $+100 \%$ Xanthosoma sagittifolium (H\&E, X100) (Color figure available online only).

\section{Preparation of Xanthosoma sagittifolium feed}

Fresh corms of $X$. sagittifolium were obtained from a local market in Ibadan. The corms were washed, peeled and parboiled for $15 \mathrm{~min}$ at low heat. The heat was maintained at $60 \pm 1^{\circ} \mathrm{C}$, below boiling point for $15 \mathrm{~min}$ at constant pressure. The parboiled corms were mashed, air-dried and crushed. Commercially pelleted rat ration were also crushed. The crushed corms were reconstituted with the commercial feed so that each $100 \mathrm{~g}$ commercial feed contained 25 , 50,75 or $100 \%$ X. sagittifolium on a weight/weight basis.

\section{Induction of diabetes mellitus}

Diabetes was induced in the normoglycemic rats by intraperitoneal injection of a single dose of alloxan monohydrate $(100 \mathrm{mg} / \mathrm{kg})$. Blood glucose levels (BGL) of the rats was monitored and rats with $\mathrm{BGL}>200 \mathrm{mg} / \mathrm{dl}$ after $48 \mathrm{~h}$ were considered diabetic and included in the study. The diabetic rats were divided into 7 groups of 5 rats each and fed as stated below:

Group 1: Diabetic untreated rats fed with commercially pelletized rat feed

Group 2: Diabetic rats fed with $25 \% \mathrm{X}$. sagittifolium feed

Group 3: Diabetic rats fed with $50 \%$ X. sagittifolium feed

Group 4: Diabetic rats fed with $75 \%$ X. sagittifolium feed

Group 5: Diabetic rats fed with $100 \%$ X. sagittifolium feed

Group 6: Diabetic rats fed with $100 \%$ X. sagittifolium feed and administered with glibenclamide $(5 \mathrm{mg} / \mathrm{kg}$ )

Group 7: Diabetic rats fed with commercially pelletized rat feed and administered with glibenclamide $(5 \mathrm{mg} / \mathrm{kg})$

Group 8: Normoglycemic rats fed with commercially pelletized rat feed

\section{Sample collection}

All rats were lightly anaesthetized using ether and sacrificed by cervical dislocation on day 15 . A pre-scrotal or midline incision was made to perform an orchidectomy as described by Oyeyemi and Ubiogoro [20]. Tunica vaginalis was excised to expose the testicles

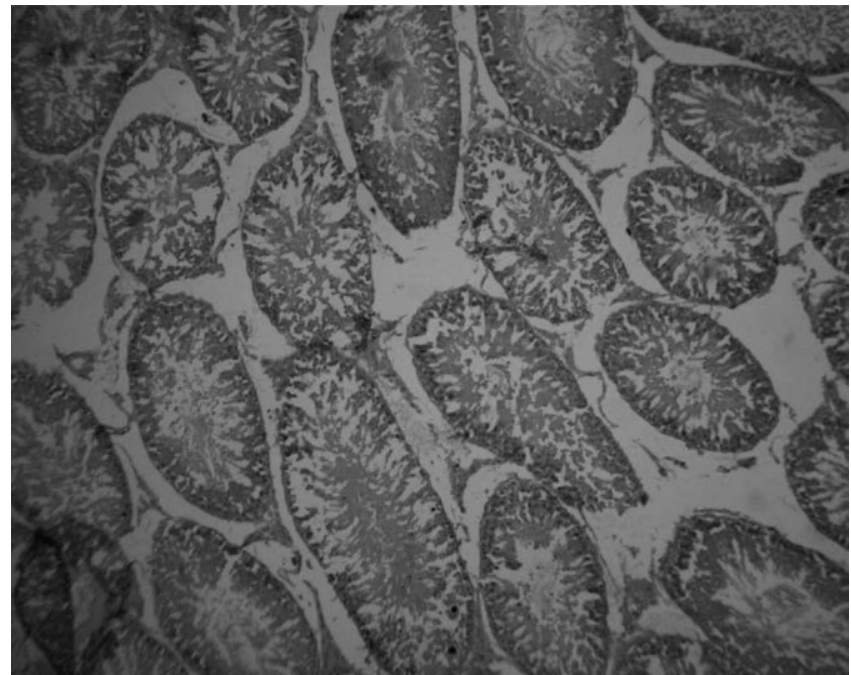

-Fig. 6 Seminiferous tubules from untreated diabetic rats fed with normal rat pellet (H\&E, X100) (Color figure available online only).

which were milked out of the incision site. Spermatic cord was ligated, excised and sperm samples were collected from the caudal epidydimis. Sperm characteristics such as sperm volume, motility, count and percentage livability were determined. Testes of the rats $(n=5)$ were also harvested for histopathological examination. The slides were stained with Hematoxylin and eosin stain. Photomicrographs were obtained and viewed in the Motic Images Plus 2.0 software to determine the seminiferous tubule diameter, germinal height and luminal diameter.

\section{Statistical analysis}

The data obtained for each group $(n=5)$ was analyzed using Oneway analysis of variance (ANOVA), and differences between means were determined using Duncan Multiple Range Test. Levels of significance was determined at $p<0.05$.

\section{Results}

\section{Primary sperm abnormality}

Rudimentary tail was the only primary abnormality observed and the number of cells with this abnormality was non-significantly $(p>0.05)$ lower in diabetic rats fed with Xanthosoma sagittifolium ( $1.4 \pm 0.36-1.8 \pm 0.36$ cells) compared to diabetic rats fed with the standard rat feed ( $2.0 \pm 0.43$ cells) or administered with glibenclamide $(2.0 \pm 0.43$ cells $)$. Normoglycemic rats ( $1.2 \pm 0.47$ cells) had significantly $(p<0.05)$ lower primary abnormality compared to the diabetic untreated rats ( $\triangleright$ Table $\mathbf{1}$ ).

\section{Secondary sperm abnormality}

Over $95 \%$ of the total number of sperm abnormalities observed were secondary abnormalities in all groups of rats. The secondary abnormalities observed were tail-less head, head-less tail, bent tail, curved midpiece, bent midpiece and looped tail. All these abnormalities were non-significantly $(p>0.05)$ higher in diabetic rats fed with $X$. sagittifolium, but most were significantly $(p<0.05)$ higher in diabetic 


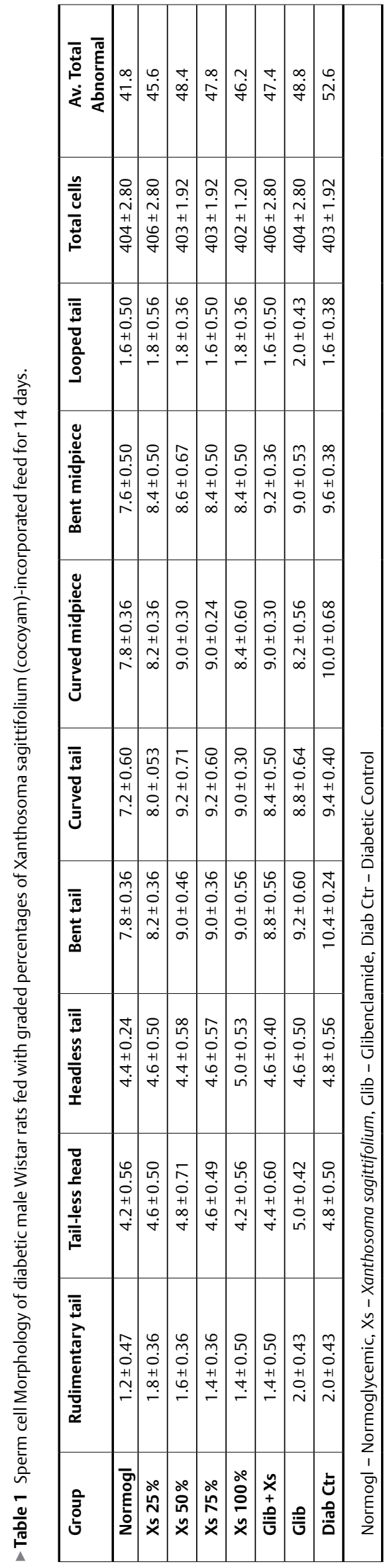

untreated rats. The total of mean abnormal cells in normoglycemic rats (41.8 cells) was lower than that observed in diabetic untreated rats ( 52.6 cells) Diabetic rats fed with X. sagittifolium had between 46.2 and 48.4 abnormal cells, while diabetic rats administered with glibenclamide had a total of 48.8 abnormal cells ( $\triangleright$ Table 1 ).

\section{Sperm characteristics}

Motility of diabetic but untreated rats ( $46 \pm 7.19 \%)$ was significantly $(p<0.05)$ reduced compared to the normoglycemic $(85 \pm 4.30 \%)$ and $X$. sagittifolium-fed diabetic rats ( $56 \pm 4.90-70 \pm 3.04 \%)$. Diabetic rats administered with glibenclamide $(54 \pm 4.90 \%)$ also had significantly $(p<0.05)$ lower motility compared to the normoglycemic rats ( $\triangleright$ Table $\mathbf{2}$ ).

The percentage liveability in $X$. sagittifolium-fed rats (95.2 $\pm 1.41-96.8 \pm 0.71 \%$ ) was not significantly different compared to the normoglycemic rats $(96.8 \pm 0.70 \%)$, but was significantly higher than that observed in diabetic untreated rats $(86.8 \pm 0.71 \%)$. Diabetic rats administered with glibenclamide $(90.6 \pm 3.31 \%)$ had non-significantly higher percentage liveability compared to diabetic untreated rats (

The sperm volume was statistically unchanged in all the rats, but sperm count was significantly $(p<0.05)$ reduced in diabetic rats $(83.8 \pm 4.90$ cells $)$ compared to the normoglycemic rats (131.6 \pm 4.66 cells). However, diabetic rats fed with X. sagittifolium (96.4 $\pm 3.60-112.0 \pm 3.95$ cells) or administered with glibenclamide $(93.6 \pm 4.46$ cells) had significantly $(p<0.05)$ higher sperm count compared to the diabetic rats ( $\vee$ Table 2 ).

\section{Histology of testes}

Histology of diabetic rat testes showed enlargement of the seminiferous tubules and lumen of the tubules (Slide B-F) compared to the normoglycemic control rats (Slide A). X. sagittifolium-fed diabetic rats showed reduction in seminiferous tubule diameter and luminal diameter (Slide B \& C) which was significantly enlarged in untreated diabetic rats (Slide F). Germinal height was statistically unchanged in all the rats ( $\triangleright$ Table 3 ).

\section{Discussion}

One of the complications of diabetes mellitus is infertility which may be due to other underlying factors such as neuropathies and impaired blood flow that is usually seen in diabetic patients [21]. These pathologies which affect function and structure of the reproductive tract and sperm cells arise from persistent elevations in blood glucose levels known as hyperglycemia. Hyperglycemia, the major clinical presentation of diabetes mellitus leads to increased generation of reactive oxygen species (ROS) which actually causes oxidative stress. It is typical for the hyperglyceamia to have developed about $10-15$ years prior to the diagnosis of DM. The result is progressive nerve and small vessel damages sequele to oxidative stress. Sequel to this biochemical event is sperm DNA damage which is caused by ROS and expressed as DNA strand breaks, chromosome deletion, chromatin cross-linking and base oxidation [22]. Results from this present study showed that diabetes mellitus affect sperm morphology and characteristics which are major determinants of fertility. A minimal percentage of sperm cell abnormalities are normal occurrences in the normal male human and animal 
- Table 2 Sperm cell characteristics of diabetic male Wistar rats fed with graded percentages of Xanthosoma sagittifolium (cocoyam)-incorporated feed for 14 days.

\begin{tabular}{|l|c|c|c|c|}
\hline Group & Motility (\%) & \% Liveability & Volume (ml) & Count (X10 $/ \mathbf{m l})$ \\
\hline Normogl & $85 \pm 4.30^{\mathrm{b}}$ & $96.8 \pm 0.70^{\mathrm{b}}$ & $5.18 \pm 0.01$ & $131.6 \pm 4.66^{\mathrm{b}}$ \\
\hline Xs 25\% & $70 \pm 3.04^{\mathrm{b}}$ & $95.8 \pm 1.50^{\mathrm{b}}$ & $5.16 \pm 0.02$ & $112.0 \pm 3.95^{\mathrm{b}}$ \\
\hline Xs 50\% & $68 \pm 3.60^{\mathrm{b}}$ & $96.8 \pm 0.71^{\mathrm{b}}$ & $5.18 \pm 0.02$ & $105.6 \pm 5.43^{\mathrm{b}}$ \\
\hline Xs 75\% & $62 \pm 3.60^{\mathrm{b}}$ & $95.2 \pm 1.41^{\mathrm{b}}$ & $5.16 \pm 0.02$ & $97.2 \pm 6.34^{\mathrm{b}}$ \\
\hline Xs 100\% & $56 \pm 4.90^{\mathrm{b}}$ & $95.2 \pm 1.41^{\mathrm{b}}$ & $5.18 \pm 0.02$ & $96.4 \pm 3.60^{\mathrm{b}}$ \\
\hline Glib+Xs100\% & $50 \pm 3.04$ & $95.8 \pm 1.50^{\mathrm{b}}$ & $5.16 \pm 0.02$ & $86.4 \pm 6.65$ \\
\hline Glib & $54 \pm 4.90^{\mathrm{b}}$ & $90.6 \pm 3.31$ & $5.18 \pm 0.02$ & $93.6 \pm 4.46^{\mathrm{a}}$ \\
\hline Diab Ctr & $46 \pm 7.19^{\mathrm{a}}$ & $86.8 \pm 0.71^{\mathrm{a}}$ & $5.18 \pm 0.02$ & $83.8 \pm 4.90^{\mathrm{a}}$ \\
\hline Normogl - Normoglycemic, Xs - Xanthosoma sagittifolium, Glib - Glibenclamide, Diab Ctr - Diabetic Control \\
\hline
\end{tabular}

- Table 3 Histological dimensions of the seminiferous tubules of rats fed with graded percentages of Xanthosoma sagittifolium (cocoyam)- incorporated feed for 14 days.

\begin{tabular}{|l|c|c|c|}
\hline Group & Sem tubule diameter & Germinal height & Luminal Diameter \\
\hline Normogl & $122.05 \pm 4.61$ & $44.78 \pm 4.34$ & $65.16 \pm 3.48$ \\
\hline Xs $5 \%$ & $170.51 \pm 5.20^{*}$ & $48.55 \pm 2.14$ & $86.79 \pm 4.51^{*}$ \\
\hline Xs 50\% & $155.38 \pm 5.20^{*}$ & $42.11 \pm 2.53$ & $73.29 \pm 3.98$ \\
\hline Xs 75\% & $153.87 \pm 6.21^{*}$ & $46.06 \pm 3.17$ & $81.64 \pm 3.42$ \\
\hline Xs 100\% & $142.39 \pm 5.46$ & $39.49 \pm 2.12$ & $58.50 \pm 3.53^{+}$ \\
\hline Glib+Xs100\% & $150.69 \pm 4.50^{*}$ & $47.42 \pm 2.85$ & $64.46 \pm 3.31$ \\
\hline Glib & $140.69 \pm 5.83^{+}$ & $46.01 \pm 1.78$ & $73.33 \pm 3.76$ \\
\hline Diab Ctr & $164.95 \pm 6.42^{*}$ & $43.31 \pm 1.77$ & $80.49 \pm 4.74$ \\
\hline$*$ - Significant value compared to Normoglycemic rats, + - Significant value compared to Diabetic Control rats \\
\hline \multicolumn{2}{|l}{} \\
\hline
\end{tabular}

due to constant exposure to oxidants which increases the rates of cellular damage [23].

Diabetes mellitus is a metabolic disease associated with increased oxidative stress caused by increased generation of ROS, as mentioned earlier, and the sequel multiorgan cellular damage associated with the disease [22]. Some researchers concluded that increased occurrence of advanced glycation end products and their receptors throughout the male reproductive tract with changes in testicular metabolite levels and spermatogenic gene expression suggest that glycation may play an integral role in oxidative stress which in turn causes sperm DNA damage [8]. Agarwal and Said [22] also reiterated that the pathogenesis of sperm damage observed as DNA damage and apoptosis is increased in seminal oxidative stress induced by diabetes.

According to the report of Adeniji et al. [24], morphologically sperm cell damage or abnormalities are classified as primary, secondary or tertiary sperm cell abnormalities. Primary abnormalities are due to impaired spermatogenesis which may have resulted from a hereditary or congenital disorder, increased ambient temperature or scrotal insulation or diseases such as diabetes mellitus. Secondary abnormalities occur after spermatogenesis and during transit of sperm cells through the epidydimis, while tertiary abnormalities occur as a result of improper handling of semen sample $[24,25]$. Increased occurrences of these abnormal sperm cells are predisposing factors to infertility [26].
In this study, a significant $(p<0.05)$ increase in these abnormal cells were observed in diabetic untreated rats, but diabetic rats fed with Xanthosoma sagittifolium-incorporated feed had lower abnormalities, better than that observed in diabetic rats treated with glibenclamide. It can be inferred from this study that sperm cell damage also occurred during the transit in the epidydimis as most abnormal cells were secondary abnormalities such as decapitated or misshapen sperm cells. This further corroborates the findings of Mallidis et al. [8] that suggested that the presence of increased advanced glycation end products in the reproductive tract may speed-up oxidative damage to the cells.

The overall sperm cell characteristics showed the adverse effect of diabetes mellitus with significantly $(p<0.05)$ reduced sperm motility, a factor that determines ability of the sperm cell to move through towards the ovum for fertilization [27]. Although the sperm volume was unaffected by the disease condition, more dead sperm cells with an overall reduction in the sperm count was observed. This finding corroborates our earlier suggestion of DNA damage and resultant cell death to the sperm cells. Feeding the diabetic rats with $X$. sagittifolium corm feed significantly reversed the effect of diabetes on these sperm characteristics. Rats fed with $25 \%$ X. sagittifolium feed showed the most appreciable result, better than what was observed in diabetic rats treated with glibenclamide.

Histology of the testes showed significantly enlarged seminiferous tubules in all diabetic rats. Although, the germinal heights 
were statistically unchanged, the luminal diameter of the tubules was increased. Thickening of the seminiferous tubules may be associated with the oxidative stress induced by diabetes as postulated by Agarwal and Said [22]. Also, the increase in luminal diameter may increase travel time through the tubules and encourage retrograde ejaculation. These anomalies were partially reversed in diabetic rats fed with $X$. sagittifolium corm feed and their effect was comparable to that observed in diabetic rats treated with glibenclamide. There is also a probability that $X$. sagittifolium inhibits generation of oxidative stress which has been directly related to these sperm cell abnormalities and the male reproductive tract.

\section{Conclusion}

$X$. sagittifolium significantly $(p<0.05)$ prevented deterioration of sperm quality and function probably due to the effect of hyperglycemia. In the overall, the chances of fertilization by sperm cells from diabetic patients will be increased as well as achievement of good glycemic control and prevention of further damage by the disease progression. Further research is however recommended to determine the exact mechanism by which $X$. sagittifolium reverse or inhibit generation of reactive oxygen species, thus alleviating oxidative stress.

\section{Conflict of Interest}

The authors declare no conflict of interest exist for the study.

\section{References}

[1] Halim EM. Lowering of blood sugar by water extract of Azadirachta indica and Abroma augusta in diabetes rats. Indian J Exp Biol 2003; 41: 636-640

[2] Heinrich M, Pieroni A, Bremner P. Plants as medicines. In: Prance G, Nesbitt M (ed.). The cultural history of plants. Routledge; 2005: 205-238 ISBN 0-415-92746-3

[3] Pandey A, Tripathi P, Pandey R et al. Alternative therapies useful in the management of diabetes: A systematic review. J Pharm Bioallied Sci 2011; 3: 504-512

[4] Kaur J. A comprehensive review on metabolic syndrome. Cardiology Research and Practice 2014; 1-22: 943162

[5] Veghari G, Sedaghat M, Joshaghani $\mathrm{H}$ et al. Association between socio-demographic factors and diabetes mellitus in the north of Iran: A population-based study. Int J Diab Mellitus 2010; 2: 154-157

[6] McDonald PA], Montenegro GJA, Cruz GCE et al. Prevalence, sociodemographic distribution, treatment and control of diabetes mellitus in Panama. Diabetology \& Metabolic Syndrome 2013; 5: 69-77

[7] Wong ND. Intensified screening and treatment of the metabolic syndrome for cardiovascular risk reduction. Preventive Cardiology 2005; 8: 47-54

[8] Mallidis C, Agbaje I, McClure $\mathrm{N}$ et al. The influence of diabetes mellitus on male reproductive function: a poorly investigated aspect of male infertility. Urologe A 2011; 50: 33-37
[9] Loeken MR. A new role for pancreatic insulin in the male reproductive axis. Diabetes 2012; 61: 1667-1668

[10] Schoeller EL, Albanna G, Frolova Al et al. Insulin rescues impaired spermatogenesis via the hypothalamic-pituitary-gonadal axis in akita diabetic mice and restores male fertility. Diabetes 2012; 61: 1869-1878

[11] Agbaje IM, Rogers DA, McVicar CM et al. Insulin dependant diabetes mellitus: Implications for male reproductive function. Hum Reprod 2007; 22: 1871-1877

[12] Jangir RN, Jain GC. Diabetes mellitus induced impairment of male reproductive functions: a review. Curr Diabetes Rev 2014; 10: 147-157

[13] Agbaje IM, McVicar CM, Schock BC et al. Increased concentrations of the oxidative DNA adduct 7,8-dihydro-8-oxo-2-deoxyguanosine in the germ-line of men with type 1 diabetes. Reprod Biomed Online 2008; 16: 401-409

[14] Mulholland J, Mallidis C, Agbaje I et al. Male diabetes mellitus and assisted reproduction treatment outcome. Reprod Biomed Online 2011; 22: 215-219

[15] Manyam BY. Diabetes mellitus, Ayurveda, and yoga. Comment. J Altern Complement Med. 2004; 10: 223-225

[16] Dham S, Shah V, Hirsch $S$ et al. The role of complementary and alternative medicine in diabetes. Curr Diab Rep 2006; 6: 251-258

[17] Acharya D, Anshu S. Indigenous herbal medicines: Tribal formulations and traditional herbal practices. Jaipur, India: Aavishkar publishers distributor; 2008: ISBN 978-81-7910-252-7 pp 440

[18] Artus M, Croft P, Lewis M. The use of CAM and conventional treatments among primary care consulters with chronic musculoskeletal pain. BMC Family Practice 2007; 8: 26-40

[19] Bloom BS, Retbi A, Dahan S et al. Evaluation of randomized controlled trials on complementary and alternative medicine. International Journal of Technology Assessment in Health Care 2000; 16: 13-21

[20] Oyeyemi MO, Ubiogoro O. Spermiogram and morphological characteristics in testicular and epididymal spermatozoa of large white boar in Nigeria. Int J Morphol 2005; 23: 235-239

[21] Ramalho-Santos ], Amaral S, Oliveira PJ. Diabetes and the impairment of reproductive function: Possible role of mitochondria and reactive oxygen species. Current Diabetes Reviews 2008; 4: 46-54 (9)

[22] Agarwal A, Said TM. Oxidative stress, DNA damage and apoptosis in male infertility: a clinical approach. BJU International 2005; 95 : 503-507

[23] Aitken RJ, De luliis GN, McLachlan RI. Biological and clinical significance of DNA damage in the male germ line. International Journal of Andrology 2008; 32: 46-56

[24] Adeniji DA, Oyeyemi MO, Olugbenga JB. Sperm morphological characteristics and mating behavior of proviron treated west african dwarf bucks with testicular degeration. Int J Morph 2010; 28: 623-626

[25] Ajala OO, Oyeyemi MO, Akusu MO et al. The effects of scrotal insulation on the testicles and spermatozoa characteristics of west African dwarf goats. Sokoto J of Veterinary Sciences 2001; 3: 44-50

[26] Oyeyipo IP, Raji Y, Emikpe BO et al. Effects of nicotine on sperm characteristics and fertility profile in adult male rats: A possible role of cessation. J Reprod Infertil 2011; 12: 201-207

[27] Yoshida M, Kawano N, Yoshida K. Control of sperm motility and fertility: diverse factors and common mechanisms. Cell Mol Life Sci 2008; 65: 3446-3457 